\title{
Understanding the Relationship between Electric Power Consumption, Technological Transfer, Financial development and Environmental Quality.
}

Bassem Kahouli ( $\square$ kahoulibassem@yahoo.fr)

Hail Community College : University of Hail

Benayan Bani Alrasheedy

Hail Community College : University of Hail

Nahla Chaaben

Hail Community College : University of Hail

Rabab Triki

Hail Community College : University of Hail

\section{Research Article}

Keywords: Electric power, Technology transfer, Environment, Financial development

Posted Date: June 22nd, 2021

DOI: https://doi.org/10.21203/rs.3.rs-591084/v1

License: (c) (i) This work is licensed under a Creative Commons Attribution 4.0 International License. Read Full License

Version of Record: A version of this preprint was published at Environmental Science and Pollution Research on October 18th, 2021. See the published version at https://doi.org/10.1007/s11356-02116900-0. 


\title{
Understanding the Relationship between Electric Power Consumption, Technological Transfer, Financial development and Environmental Quality.
}

\author{
Bassem Kahouli a,b, ${ }^{*}$, Benayan Bani Alrasheedy ${ }^{\text {a }}$, Nahla Chaaben ${ }^{\text {a }}$, Rabab Triki ${ }^{\text {a }}$ \\ a University of Ha'il, Community College, Ha'il, Saudi Arabia. \\ ${ }^{\mathrm{b}}$ University of Sousse, Higher Institute of Finance and Taxation, Sousse, Tunisia. \\ kahoulibassem@yahoo.fr.
}

\section{Abstract}

This research paper attempts to investigate both the long-run and causality relationship among electric power consumption (EPC), technological transfer, financial development (FD), and environmental quality for the Saudi Arabia (KSA) economy from 1980 to 2019.

In doing so, we propose a carbon emission function tested by incorporating multi-steps techniques such as autoregressive distributed lag (ARDL) has been exploited to determine the existence of cointegration or no; while vector error correction model (VECM) has been applied to decide the direction of causality. In this paper we have proposed two proxies of technological transfer, namely imported technology (MT) and Technical cooperation grants (TCG). The results indicate the existence of cointegration between the concerned series. Besides, the existence of a feed-back effect among variables (except TCG) in the long-run. However, in the short run feed-back effect exists among EPC and EnvQ; MT and EnvQ; EPC and MT. Thus, the paper provides original visions for policy makers to encourage the technological transfer by financing and supporting the electric energy sector which constitutes the main locomotive to improve the environment quality for the KSA.

Keywords: Electric power, Technology transfer, Environment, Financial development JEL classification : C32, C52, O11, Q43 


\section{Introduction}

In recent decades, climate change due to carbon $\left(\mathrm{CO}_{2}\right)$ emissions is one of the major environmental, political and economic challenges since it affects the whole world. Thus, it is disrupting national economies, degrading the environment, affecting lives, changing weather patterns, rising sea levels, and weather events are becoming more extreme, etc. (United Nations, 2018). Therefore, improved EnvQ represents an ecological, economical and sociological issue of importance and concern worldwide. Hence, humanity is required to think and act responsibly and determine sustainable solutions especially in countries with highly energy consumption and economic growth. That could be explained as the production process is conducted by the demand for energy. Whereas this demand in turn is conducted by demographic developments, level of economic activities, and by technological and structural changes (Yeager et al., 2011). Nevertheless, efforts to respond to the progressive energy demand coupled with the mitigation of climate change represent a hard task for governments that need several technological innovations, FD with a rational environmental policy.

In this paper we will focus on electricity as the main form of final energy used to power homes, transport, trades, communications and productions. According to Zhang et al. (2013) the electricity generation is the principal source of carbon, representing more than $40 \%$ of global $\mathrm{CO}_{2}$ emissions that contribute to degradation of the EnvQ. In fact, in the

47 KSA, growth and exports rely almost completely on industries that benefit from circumstantial advantages related to power and raw material provision, knowing that these resources will deplete over time. Furthermore, the Saudi industrial sector is heavily concentrated in these basic industries, as they represent $56 \%$ of GDP and more than $71 \%$. 
51 of exports, relying strongly on the KSA circumstantial advantages related to energy. In

52 addition, the KSA economy aims to achieve significant performance for key factors of

53 transformative industries such as innovation, ability to attract and retain talents and

54 government regulations. This situation made the Kingdom fronted to many challenges such

55 as improving the competitiveness of the electricity sector through restructuring and

56 exploring power exportation opportunities, increasing the share of the renewable energy

57 sector in local consumption and enhancing the competitiveness of the energy sector. In the

58 same time, reducing environmental degradation by creating a friendly climate while

59 balancing the need for reducing fiscal burden with need for focused incentives; in

60 particular, reduce electricity consumption, are the main author challenges to the KSA. In

61 this context, this study aims to investigate the role played by energy specifically EPC,

62 technological transfer and FD on EnvQ. As well to understand the long-run and the causal

63 relationships between variables, we applied a multi-steps methodology based mainly on

64 ARDL and VECM Granger causality approach. This methodology supports to demonstrate

65 the effects of relevant technology, financial and economic factors to promote the quality of

66 the environment in the KSA. To the best of our knowledge, there has never been any

67 endeavors to investigate both the long-run and the interactions among EPC, technological

68 transfer, FD and EnvQ for the KSA economy.

69 The reminder of this manuscript is organized as below: Section 2 exposes a literature

70 review on EPC, technological transfer, FD and EnvQ. Section 3 describes data and model

71 specification. Section 4 provides econometrics methodology for this research paper.

72 Section 5 reveals and discusses the empirical results. Section 6 recapitulates and endings

73 by proposing certain recommendations and policy implications. 


\section{Literature review}

The existing environment and energy literature have rarely examined the relationships among EPC, technological transfer, FD and EnvQ especially in the KSA economy. This current paper exposes specifically the most relevant studies which are related to our variables of interest by classified the existent reviews in three research strands. The first one examines the relationships among EPC, technological transfer and EnvQ. The second strand investigates the relationships between EPC, FD and EnvQ while the third explores the associations among FD, technology transfer and EnvQ. As Table1 proves, the discoveries of these studies are inconclusive.

\subsection{EPC-technological transfer-environment nexus}

The studies on the relationships among energy, technology and environment has been the recent trend in the environment and energy literature (Zang et al., 2013; Mariano et al., 2016; Wang and Wang., 2018; Pang and Tao, 2018; Kahouli, 2018; Rumayor et al., 2019; Zafar et al., 2020, Altıntas and Kassouri, 2020). To be more specific, Mansouri et al. (2013) have studied the Saudi electricity sector focused on 18 different forecast figures for $\mathrm{CO}_{2}$ emissions engendered by electricity for each year from 2010 to 2025 . They have suggested that Saudi government must declare objectives to reduce $\mathrm{CO}_{2}$ emissions and to invest seriously in evolving its own progressions and innovations in energy technologies. In the case of China, Wang and Wang (2018) have investigated the relationship among MT and environmental degradation for the period 1980-2011. Based on the ARDL and the VECM they deduce that imported technologies principally lead to $\mathrm{CO}_{2}$ emissions in the long-run. The findings have mentioned the existence of feed-back effects among MT and environment; energy use and environment. Furthermore, Hodson et al. (2018) have 
99 estimated the importance of technology innovation, the fuel prices, and $\mathrm{CO}_{2}$ emissions on 100 electric power productions from four U.S. energy-economic models through the year 2050. 101 Results have shown that realizing innovation aims declines $\mathrm{CO}_{2}$ emissions owing to 102 improved energy efficiency.

103 In the same context, Cheng et al. (2019) have studied the associations among the 104 developments of patents as a technological innovation indicator and $\mathrm{CO}_{2}$ emissions for 36 105 OECD countries from 1996 to 2015 by using a panel quantile regression model. Empirical 106 findings have shown that the coefficient values are not significant and even positive with $107 \mathrm{CO}_{2}$ emissions at different quantile levels. Further, Ali et al. (2019) have investigated the 108 Kuznets curve of Malaysia over a period of 1985 to 2016 by using the ARDL method. The 109 results have suggested that improved technology can lead to a cleaner environment. 110 Consequently, there are bi-directionally linked between environment and energy 111 consumption as well as between structural changes and technological innovation. In 112 another paper, Alola et al. (2019) have analyzed the role of renewable energy consumption 113 and economic growth to ameliorate EnvQ by using ARDL approach to 16 European Union 114 countries for the period 1997-2014. Empirical results have approved that renewable energy 115 enhances EnvQ. Focusing in Thailand, Wattana and Wattana (2020) have developed three 116 scenarios that represent penetration levels of electricity generated from renewable energy 117 for the period 2018-2037. The results have indicated the importance of technology 118 innovation in renewable energy that affects positively the electricity generation with a 119 particular focus on energy security and $\mathrm{CO}_{2}$ emissions mitigation potentials. Recently, 120 Sinha et al. (2020) have studied the link between technological innovation and EnvQ in 121 Middle East and North African (MENA) countries for the period of 1990-2017. They have 
122 used the Quantile cointegration and Quantile Autoregressive Granger causality. Empirical

123 finding indicates mutual dependence among technological progression and ambient air

124 pollution. More recently, Zameer et al. (2020) have explored the effects of technological

125 innovation and energy use on $\mathrm{CO}_{2}$ emissions in the Indian economy during the period

126 1985-2017 by employing the ARDL and the VECM methods. They have confirmed the

127 existence of long-term cointegration and energy consumption positively stimulates $\mathrm{CO}_{2}$

128 emissions. Whereas, technological innovation negatively reinforces environment quality

129 in the long term.

\subsection{EPC-FD-environment nexus}

131 The relationship between EPC, FD and environment has been well proven this is last 132 years for instance Sadorsky (2011); Shahbaz (2013); Farhani and Ozturk (2015); Kahouli 133 and Omri, (2017); Cetin et al. (2018); Kahouli (2018); Xu et al. (2018); Ouyang et al. 134 (2018); Wang (2019); Eren et al. (2019); Zang (2019); Shahbaz et al. (2020); Acheampong 135 et al. (2020). Those studies across countries using both panel and time-series data by 136 incorporating several econometric techniques like as correlation analysis, bivariate 137 causation, unit root tests, multivariate cointegration, ARDL, VECM, ordinary least square 138 (OLS), full modified OLS (FMOLS), dynamic OLS (DOLS), generalized method of 139 moments (GMM), linear and non-linear dynamic panel models. Get started by Shahbaz 140 (2013) who has explored the nexus among financial instability, environmental degradation 141 and energy use in Pakistan from 1971 to 2009 by employing ARDL and VECM. The 142 empirical results have shown that a long-run association among series can be identified as 143 well as financial instability declines EnvQ. Likewise, Farhani and Ozturk (2015) have 144 examined the causal relationship among $\mathrm{CO}_{2}$ emissions, economic growth, energy 145 consumption, and FD in Tunisia from 1971 to 2012 by applying ARDL and VECM. The 
146 empirical findings have indicated that the FD stimulates $\mathrm{CO}_{2}$ emissions. Besides, Bekhit et

147 al. (2017) explored the dynamic causal relationships between $\mathrm{CO}_{2}$, FD and energy use for

148 Gulf Cooperation Council (GCC) countries from 1980 to 2011. The results suggest a long-

149 term causal relationship between $\mathrm{CO}_{2}$ emissions and FD for all GCC countries except the

150 United Arab Emirates. Consequently, there is a long-term and one-way direction causality

151 from carbon emissions to energy consumption for some countries such as the KSA, UAE

152 and Qatar. Thus, the financial systems of GCC countries should consider environmental

153 aspects in their decisions while preserving economic growth. In the same line, Kahouli

154 (2018) has studied the four-way associations linkages among EPC, $\mathrm{CO}_{2}$ emissions, FD,

155 R\&D and real GDP for the Mediterranean countries from 1990 to 2016 by using SUR,

156 3SLS, and GMM estimators. Empirical results confirm the existence of strong feedback

157 effects between variables. In the same context, $\mathrm{Xu}$ et al. (2018) have explored the

158 contribution of FD to environmental degradation in the KSA by applying ARDL and

159 VECM methods to observe the long-term causal relationship. The results have shown that

160 FD contributes to the degradation of the quality of the environment and that EPC is the

161 principal responsible for the environmental degradation in the KSA. Alternatively, the

162 causality is mutual and bidirectional between long-term $\mathrm{CO}_{2}$ emissions and FD. In another

163 perspective, Shahbaz et al. (2020) have examined the link between EPC, FD and

164 environment by using the Toda-Yamamoto causality test. The finding indicated that FD

165 raises $\mathrm{CO}_{2}$ emissions and real GDP is completely associated to environmental degradation.

166 While, EPC improves the EnvQ. Acheampong et al. (2020) have explored the impact of

167 the financial market and energy consumption on $\mathrm{CO}_{2}$ emissions intensity. They have used 
168 the GMM technique for 83 countries over the period 1980-201, they have revealed that 169 financial markets moderate growth and energy to stimulate environment degradation.

170

171

172

173 174

\subsection{Financial development-technological transfer-environment nexus}

In the recent literature, there are slight studies trying to investigate our third strand which purposes to study the link among FD, technology transfer and environment (Khan et al., 2018; Amri, 2018; Demir et al., 2019; Kahouli, 2019; Ibraheim, 2020; Nguyen et al., 2020; Avom et al., 2020; Aluko and Obalade, 2020). For instance, Khan et al. (2018) have examined the link among information and communication technology (ICT), FD, and EnvQ in emerging countries from 1990 to 2015 by employing mean group (MG) and augmented mean group (AMG) methods. The empirical findings have shown that the moderating impact of ICT and FD accelerate the environmental degradation. Likewise, Amri (2018) has studied the linkage between $\mathrm{CO}_{2}$ emissions, ICT and FD, in Tunisia from 1975 to 2014 by using ARDL. Empirical results have indicated an insignificant impact of ICT on $\mathrm{CO}_{2}$ emissions as a measure of pollution; FD negatively affects the EnvQ. In the case of Turkey, Demir et al. (2019) have used the ARDL cointegration approach to examine the relationship between $\mathrm{FD}$, the number of national patents and $\mathrm{CO}_{2}$ emissions from 1971 to 2013 . The results have revealed that the relationship among the level of $\mathrm{CO}_{2}$ emissions and the number of national patents represents an inverted U-curve. Therefore, FD has positive effects on $\mathrm{CO}_{2}$ emissions. In another study, Ibraheim (2020) have studied the nexus between $\mathrm{CO}_{2}$ emissions, technological innovation and FD in Egypt from 1971 to 2014 by using ARDL, FMOLS, DOLS and Toda-Yamamoto approaches. The empirical results have shown that technological innovation and alternative energy resources advance EnvQ, FD deteriorates it. The results from Toda-Yamamoto approach expose that 
191 environmental degradation generates technological innovation and FD generates 192 environmental degradation. In the same order, Nguyen et al. (2020) have studied the effect 193 of FD, ICT and innovation on EnvQ (proxied by $\mathrm{CO}_{2}$ emissions) in selected 13 countries 194 in the G20 from 2000 to 2014 by using FMOLS and Quantile Panel. The empirical findings 195 have indicated that ICT has an unintended impact on EnvQ through FD. Recently, Avom 196 et al. (2020) have tested how ICT influences EnvQ in 21 Sub-Saharan Africa (SSA) from 1971996 to 2014. They have concluded that ICT has an unintended impact on EnvQ through 198 energy use, trade and FD. More recently, Aluko and Obalade (2020) have explored the 199 technology impact of FD on EnvQ in 35 in SSA countries for the period 198-2014 by using 200 the AMG estimator. The empirical results have mentioned that FD has an unfavorable 201 technology impact on EnvQ.

202 According to those studies the empirical findings are conflicted. Probably, the principal 203 reason for these various results derives from the data, econometric approaches and the level 204 of development of the country in which a study is being carried out. Thus, it is essential to 205 carry out new exploration concerning the relationship between EPC, technological transfer, 206 FD and EnvQ.

207

208

209

210 
Table 1. Summary of empirical studies on EPC, technological transfer financial development and Environmental Quality relationship.

\begin{tabular}{|c|c|c|c|c|}
\hline Author(s) & Country/Region & Period & Methodology & Empirical findings \\
\hline \multicolumn{5}{|c|}{ EPC-technological transfer-environment nexus. } \\
\hline Mariano et al. (2016) & $\begin{array}{l}\text { BRICS and the G7 } \\
\text { countries }\end{array}$ & $1993-2010$ & Non parametric analysis (DEA) & $\begin{array}{l}\text { Technology contributes efficient energy and low energy } \\
\text { consumption helping to realize the best environment. }\end{array}$ \\
\hline Wang and Wang (2018) & China & $1980-2011$ & ARDL and VECM & $\begin{array}{l}\text { Feed-back effects between MT and } \mathrm{CO}_{2} \text { emissions; energy } \\
\text { consumption and } \mathrm{CO}_{2} \text { emissions. }\end{array}$ \\
\hline Hodson et al. (2018) & USA & $\begin{array}{l}\text { Through the } \\
\text { year } 2050 \text {. }\end{array}$ & $\begin{array}{l}16 \text { models comparative } \\
\text { cross sector analysis }\end{array}$ & $\begin{array}{l}\text { Innovation decreases } \mathrm{CO}_{2} \text { emissions due to increased } \\
\text { energy efficiency and low-carbon generation. }\end{array}$ \\
\hline Cheng and al. (2019) & 36 OECD countries & $1996-2015$ & Panel quantile regression model & $\begin{array}{l}\text { The coefficient values are not significant and even positive } \\
\text { with } \mathrm{CO}_{2} \text { emissions at different quantile levels. }\end{array}$ \\
\hline Alola et al. (2019) & 16 Europeans countries & $1997-2014$ & A panel ARDL approach & $\begin{array}{l}\text { There is an influence of ITC on energy consumption that } \\
\text { contributes to an effect on the environment perspective. }\end{array}$ \\
\hline Zafar et al. (2020) & OCDE countries & $1990-2015$ & Second generation methods & Energy consumption affects EnvQ and ITC declines $\mathrm{CO}_{2}$. \\
\hline Zameer et al. (2020) & Indian & $1985-2017$ & ARDL and VECM & $\begin{array}{l}\text { Energy positively enhances } \mathrm{CO}_{2} \text {. Whereas, technological } \\
\text { innovation negatively reinforces } \mathrm{CO}_{2} \text { in the long term. }\end{array}$ \\
\hline \multicolumn{5}{|c|}{ EPC-FD-environment nexus. } \\
\hline Shahbaz (2013) & Pakistan & 1971-2009 & ARDL and VECM & $\begin{array}{l}\text { There are long-run relationships between variables and } \\
\text { financial instability decrease EnvQ. }\end{array}$ \\
\hline Farhani and Ozturk (2015) & Tunisia & 1971-2012 & ARDL and VECM & FD expenses of environmental pollution. \\
\hline Bekhit et al. (2017) & GCC countries & 1980- 2011 & ARDL approach & $\begin{array}{l}\text { There are long-term causal relationships among } \mathrm{CO}_{2}, \mathrm{FD} \text { for } \\
\text { all GCC countries except the United Arab Emirates (UAE). }\end{array}$ \\
\hline Xu et al. (2018) & Saudi Arabia & $1971-2016$ & ARDL and VECM & $\begin{array}{l}\text { FD contributes to the degradation of the EnvQ and EPC is } \\
\text { the main responsible for the increase in } \mathrm{CO}_{2} \text { emissions. }\end{array}$ \\
\hline
\end{tabular}




\begin{tabular}{|c|c|c|c|c|}
\hline Kahouli (2018) & Mediterranean countries & $1990-2016$ & SUR, 3SLS and GMM & Existence of feedback effects between ECP, $\mathrm{CO}_{2}$ and FD. \\
\hline Cetin et al. (2018) & Turkey & $1960-2013$ & Cointegration test and VECM & $\mathrm{CO}_{2}$ is determined by EPC, and FD. \\
\hline Wang (2019) & BRICS countries & $1992-2013$ & GMM method & $\begin{array}{l}\text { Energy consumption reduces environmental pollution and } \\
\text { there is an N-shaped relationship between FD and pollution. }\end{array}$ \\
\hline Eren et al. (2019) & India & $1971-2015$ & DLOS & $\begin{array}{l}\text { Positive impact of FD on EPC and a bidirectional causality } \\
\text { between EPC and FD driven in the long run in India. }\end{array}$ \\
\hline Shahbaz et al. (2020) & UAE & $1975-2014$ & $\begin{array}{l}\text { Cointegration test and } \\
\text { TodaYamamoto causality test }\end{array}$ & $\begin{array}{l}\text { FD increases } \mathrm{CO}_{2} \text { emissions and electricity improves the } \\
\text { quality of the environment. }\end{array}$ \\
\hline Acheampong et al. (2020) & 83 countries & $1980-2015$ & $\begin{array}{l}\text { GMM approach and a } \\
\text { comprehensive panel data }\end{array}$ & $\begin{array}{l}\text { Financial markets develop moderate energy to influence } \\
\mathrm{CO}_{2} \text { emission intensity. }\end{array}$ \\
\hline \multicolumn{5}{|c|}{ FD-technological transfer-environment nexus. } \\
\hline Khan et al. (2018) & Emerging countries & $1990-2015$ & $\begin{array}{l}\text { MG and AMG estimation } \\
\text { methods }\end{array}$ & $\begin{array}{l}\text { The moderating effect of ICT and FD stimulate the level of } \\
\mathrm{CO}_{2} \text { emissions. }\end{array}$ \\
\hline Amri (2018) & Tunisia & $1975-2014$ & ARDL Cointegration & $\begin{array}{l}\text { Insignificant impact of ICT on } \mathrm{CO}_{2} \text { emissions as a measure } \\
\text { of pollution. However, FD negatively affects the EnvQ. }\end{array}$ \\
\hline Demir et al. (2019) & Turkey & $1971-2013$ & ARDL Cointegration & $\begin{array}{l}\text { Inverted U-curve between } \mathrm{CO}_{2} \text { emissions and the number of } \\
\text { national patents. FD effects positively on } \mathrm{CO}_{2} \text { emissions. }\end{array}$ \\
\hline Ibraheim (2020) & Egypt & $1971-2014$ & $\begin{array}{l}\text { ARDL, FMOLS, DOLS, and } \\
\text { Toda-Yamamoto approaches }\end{array}$ & $\begin{array}{l}\text { Technological innovation and alternative energy resources } \\
\text { improve EnvQ; FD deteriorates it. }\end{array}$ \\
\hline Nguyen et al. (2020) & 13 countries in G20 group & $2000-2014$ & $\begin{array}{l}\text { Quantitative analysis, OLS and } \\
\text { Quantile Panel }\end{array}$ & ICT has an indirect effect on EnvQ through FD. \\
\hline Avom et al. (2020) & 21 Sub-Saharan Africa & $1996-2014$ & Stochastic regression & ICT has an indirect effect on EnvQ through FD. \\
\hline Aluko and Obalade (2020) & 35 Sub-Saharan countries & 1985-2014 & Dumitrescu-Hurlin panel test & FD has an unfavorable technology effect on EnvQ. \\
\hline
\end{tabular}




\section{3. Data and model specification}

\section{3.1. Data}

214 In order to figure out the nexus between EPC, technological transfer, FD and EnvQ, diverse

215 proxies have been employed to measure technology and EnvQ in the previous studies. This paper 216 measures environmental quality (EnvQ) as $\mathrm{CO}_{2}$ emissions from electricity and heat production, 217 total (\% of total fuel combustion). Likewise, electric power consumption (EPC) determines the 218 production of power plants and combined heat and power plants (kWh per capita). To identify the 219 technological transfer, we propose two proxies. The first proxy determines the imported 220 technology (MT), we utilize computers, communications and other services (\% of commercial 221 service imports) including such activities as international telecommunications; computers. The 222 second variable as a proxy of the technological transfer is technical cooperation grants (TCG). 223 Thus, TCG comprise free-standing TCG, which are proposed to finance the transfer of technical 224 and managerial skills or of technology; and investment linked TCG, which are required to reinforce 225 the capacity to achieve specific investment projects (current U.S. dollars). Financial development 226 (FD) defines domestic credit to the private sector (\% of GDP). All the data are collected from the 227 world development indicators (WDI) online database (Appendix.1). The study covers annual data 228 over the period of 1980-2019 for the KSA economy. The period of the current study is selected on 229 the accessibility of data.

230 Therefore, table 2 determines the descriptive statistics of these series for the KSA economy. It 231 denotes that all series are normally distributed as exposed by statistics of Jarque-Bera test. Pairwise 232 correlation analysis denotes that EPC, TCG and FD are positively associated with EnvQ. Likewise, 233 TCP and FD are positively associated with EPC. However, the correlation between MT with EnvQ 234 and EPC are negative. Also, the correlation analysis indicates that TCP and FD are negatively 235 linked with MT. 
Table 2. Descriptive statistics and correlation matrix.

\begin{tabular}{lccccc}
\hline & $\operatorname{lnEnv}$ & $\operatorname{lnEPC}$ & $\operatorname{lnMT}$ & $\ln$ TCG & $\operatorname{lnFD}$ \\
\hline Mean & 2.731 & 8.606 & 3.870 & 16.512 & 3.237 \\
Median & 2.787 & 8.637 & 4.154 & 16.506 & 3.292 \\
Max & 3.015 & 9.371 & 4.425 & 16.911 & 4.097 \\
Min & 2.351 & 7.586 & 2.202 & 15.992 & 1.917 \\
SD & .169 & .456 & .573 & .195 & .548 \\
Skewness & -0.495 & -0.287 & -1.007 & -0.085 & -0.496 \\
Kurtosis & 2.328 & 2.361 & 3.248 & 3.294 & 2.891 \\
Jarque-Bera & 2.386 & 1.230 & 6.866 & 0.193 & 1.659 \\
Probability & 0.303 & 0.540 & 0.322 & 0.907 & 0.436 \\
& & & & & \\
InEnv & 1 & & & & \\
InEPC & 0.483 & 1 & & & \\
InMT & -0.006 & -0.596 & 1 & & \\
InTCP & 0.367 & 0.146 & -0.123 & 1 & \\
InFD & 0.576 & 0.971 & -0.588 & 0.235 & 1 \\
\hline
\end{tabular}

Notes: Max., Min. and SD are maximum, minimum and standard deviation, respectively. Data period is 1980-2019 for Saudi Arabia.

\subsection{Model specification}

The main purpose of the current study is to investigate the determinants of EnvQ in the case of the KSA economy by taking into account the role played by EPC, technological transfer and FD. The relationship among the level of EnvQ $\left(\mathrm{CO}_{2}\right.$ emissions) as endogenous variable with the different exogenous and control variables have long been examined simultaneously (Jayanthakumaran et al., 2012; Wang and Wang, 2018; Kahouli, 2018; Shahbaz et al., 2020). The present study considers the following EnvQ function:

$$
E n v Q=f(E P C, M T, T C G, F D)
$$

The econometric model for this study is specified as follows:

$$
E n v Q_{t}=\alpha_{0}+\alpha_{1 t} E P C_{t}+\alpha_{.2 t} M T_{t}+\alpha_{3 t} T C G_{t}+\alpha_{4 t} F D_{t}+\varepsilon_{t}
$$

$$
\text { The model transformed to log-linear functional form and stated as below: }
$$


where EnvQ shows, carbon dioxide emissions from electricity and heat production, total (\% of total fuel combustion), EPC is electric power consumption per capita, MT is imported technology measured as computer, communications and other services imports, TCG is Technical cooperation grants; the both variables are used as proxies for technological transfer, FD shows domestic credit to private sector proxy for financial development. $\alpha_{0}, \mathrm{t}$, and $\varepsilon$ are respectively the fixed country effect, the time and the residual term.

\section{Econometric methodology}

To study the association among EPC, technological transfer, FD and EnvQ for the KSA we propose multi-steps methodology based mainly on ARDL procedure and VECM. The ARDL procedure used to estimate the long run and short run relationship presents several advantages:

267 First, it can be applied without having the same order of integration or to have the same optimal lags for all variables in the system. Second, it is particularly useful for this study because he doesn't require large samples or absence of endogeneity between regressors to obtain an efficient estimator. Third, the ARDL does not demand to have multiple equations because a single reduced-

$$
\begin{aligned}
& \Delta \ln E n v Q_{t}=\alpha_{0}+\sum_{k=1}^{n} \alpha_{1 k} \Delta \ln E n v Q_{(t-k)}+\sum_{k=1}^{n} \alpha_{2 k} \Delta \ln E P C_{(t-k)}+\sum_{k=1}^{n} \alpha_{3 k} \Delta \ln M T_{(t-k)}+\sum_{k=1}^{n} \alpha_{4 k} \Delta \ln T C G_{(t-k)} \\
& +\sum_{k=1}^{n} \alpha_{5 k} \Delta \ln F D_{(t-k)}+\beta_{1} \ln E n v Q_{(t-1)}+\beta_{2} \ln E P C_{(t-1)}+\beta_{3} \ln M T_{(t-1)}+\beta_{4} \ln T C G_{(t-1)}+\beta_{5} \ln F D_{(t-1)}+\varepsilon_{t}
\end{aligned}
$$

$274 \Delta$ represents the first difference and $\varepsilon_{1}$ indicates the residual term. The null hypothesis of no 275 cointegration among the variables is $\beta_{1}=\beta_{2}=\beta_{3}=\beta_{4}=\beta_{5}=0$. 
At the start we will verify the order of integration of the variables by utilizing Augmented DickeyFuller (ADF) test of Dickey and Fuller (1981) and Phillips-Perron (PP) test of Phillips and Perron (1988). Once proving integration, the next step will be the choice of appropriate criteria; we will propose Akaike Information Criterion (AIC) for this paper to identify appropriate lag length. The AIC preserved in view to choose the smallest lag length value and to reduce the loss of a degree of freedom (Jayanthakumaran et al., 2012 and Ahmed et al., 2015). Likewise, to capture the dynamic results, an AIC is envisaged more superior and effective as compared to Schwarz Information Criterion (SIC), which delivers more effective and reliable findings. When the lag length is designated, we will examine the cointegration among variables, doing so, we will suggest Johansen cointegration in our study. After confirmation of cointegration among variables, we will try to examine the long-run and short-run relationship. Furthermore, to verify the constancy of the model and to confirm finding for policy-maker, this paper applies robustness tests, i.e., Reset test, ARCH test and LM test. The cumulative sum of recursive residual (CUSUM) and cumulative sum of the square of recursive residual (CUSUMsq) tests will be used to verify the stability of the model to recommend policies for implication. Finally, we will turn to examine the direction of causality among variables. In this context, we will propose the VECM Granger causality approach in order to determine the direction of causality among EPC, MT, TCG and FD. Consequently, the empirical equation of VECM Granger causality approach is modeled as follows:

$$
\left[\begin{array}{l}
\ln E n v Q_{t} \\
\ln E P C_{t} \\
\ln M T_{t} \\
\ln T C P_{t} \\
\ln F D_{t}
\end{array}\right]=\left[\begin{array}{l}
\alpha_{1} \\
\alpha_{2} \\
\alpha_{3} \\
\alpha_{4} \\
\alpha_{5}
\end{array}\right]+\sum_{k=1}^{n}\left[\begin{array}{l}
\alpha_{11 k} \alpha_{12 k} \alpha_{13 k} \alpha_{14 k} \alpha_{15 k} \\
\alpha_{12 k} \alpha_{22 k} \alpha_{23 k} \alpha_{24 k} \alpha_{25 k} \\
\alpha_{13 k} \alpha_{23 k} \alpha_{33 k} \alpha_{34 k} \alpha_{35 k} \\
\alpha_{14 k} \alpha_{24 k} \alpha_{34 k} \alpha_{44 k} \alpha_{45 k} \\
\alpha_{15 k} \alpha_{25 k} \alpha_{35 k} \alpha_{45 k} \alpha_{55 k}
\end{array}\right] *\left[\begin{array}{l}
\ln E n v Q_{t-k} \\
\Delta \ln E P C_{t-k} \\
\Delta \ln M T_{t-k} \\
\Delta \ln T C P_{t-k} \\
\Delta \ln F D_{t-k}
\end{array}\right]+\left[\begin{array}{l}
\gamma_{1} \\
\gamma_{2} \\
\gamma_{3} \\
\gamma_{4} \\
\gamma_{5}
\end{array}\right] * E C T_{t-1}+\left[\begin{array}{l}
\varepsilon_{1 t} \\
\varepsilon_{2 t} \\
\varepsilon_{3 t} \\
\varepsilon_{4 t} \\
\varepsilon_{5 t}
\end{array}\right]
$$

When the error correction term $E C T_{t-1}$ is statistically significant with a negative sign; it is the 
297 indication of long-run causality. Furthermore, we employ Wald test to calculate the short-run

298 causality.

299

300

301

302

303

304

305

306

\begin{tabular}{|c|c|c|c|c|c|}
\hline \multirow{2}{*}{ Variables } & \multicolumn{2}{|c|}{ ADF test } & \multicolumn{2}{|r|}{ PP test } & \multirow{2}{*}{$\begin{array}{l}\text { Order of } \\
\text { Integration }\end{array}$} \\
\hline & Level & First difference & Level & First difference & \\
\hline \multirow{2}{*}{$\operatorname{lnEnvQ}$} & -2.253 & -7.030 & -2.224 & -7.041 & \multirow{2}{*}{$\mathrm{I}(1)$} \\
\hline & $(0.1917)$ & $(0.003)^{*}$ & $(0.2012)$ & $(0.000)^{*}$ & \\
\hline \multirow{2}{*}{$\operatorname{lnEPC}$} & -2.821 & -6.234 & -2.738 & -6.234 & \multirow{2}{*}{$\mathrm{I}(1)$} \\
\hline & $(0.064)$ & $(0.001)^{*}$ & $(0.176)$ & $(0.005)^{*}$ & \\
\hline \multirow{2}{*}{$\ln M T$} & -2.012 & -6.291 & -1.879 & -7.984 & \multirow{2}{*}{$\mathrm{I}(1)$} \\
\hline & $(0.2805)$ & $(0.009)^{*}$ & $(0.337)$ & $(0.001) *$ & \\
\hline \multirow{2}{*}{$\ln T C G$} & -0.799 & -7.047 & -1.338 & -13.433 & \multirow{2}{*}{$\mathrm{I}(1)$} \\
\hline & $(0.807)$ & $(0.006)^{*}$ & $(0.601)$ & $(0.000)^{*}$ & \\
\hline \multirow{2}{*}{$\ln F D$} & 0.135 & -5.388 & -2.104 & -5.066 & \multirow{2}{*}{$\mathrm{I}(1)$} \\
\hline & $(0.963)$ & $(0.000)^{*}$ & $(0.243)$ & $(0.007)^{*}$ & \\
\hline
\end{tabular}

307

\section{Empirical findings and discussion}

\subsection{Stationary tests}

This paper applied the ADF and PP unit root tests on the natural logarithms of the variables in level and difference forms to explore the relationship between, EPC, technological transfer, FD and EnvQ in the KSA. The results described in Table 3 reveal that all the variables of the study are stationary at the first difference, which justifies the application of the ARDL technique.

Note: * indicates the level of significance at $1 \%$.

\subsection{ARDL cointegration tests}

After proving that all the variables share the same integration properties, we move now to investigate the long-run and short-run coefficients by using the ARDL cointegration method. This technique is established on two main steps. Beginning with the first step, the long-run relationship of Eq. (4) will be clarified by investigating the order of lag. This one will be involved to estimate VAR or VECM models that is attained from unrestricted VAR model and by maximized likelihood ratio (LR) criterion, minimized final prediction error (FPE), AIC, SIC, and Hannan Quinn (HQ) 
315 criteria. The results of this stage lead to conserve the optimal lag which is found to be 1 , except

316 AIC (Table 4).

317 Table 4. Lag length selection criteria for cointegration VAR lag order selection criteria.

$318 \quad{ }^{\mathrm{i}}$ Indicates lag order selected by the criterion.

\begin{tabular}{lcccccc}
\hline Lag & LogL & LR & FPE & AIC & SC & HQ \\
\hline $\mathbf{0}$ & 30.350 & NA & $1.75 \mathrm{e}-07$ & -1.370 & -1.1526 & -1.293 \\
$\mathbf{1}$ & 159.377 & $216.206^{\mathrm{i}}$ & $6.41 \mathrm{e}-10^{\mathrm{i}}$ & -6.993 & $-5.687^{\mathrm{i}}$ & $-6.532^{\mathrm{i}}$ \\
$\mathbf{2}$ & 186.050 & 37.487 & $6.33 \mathrm{e}-10$ & -7.083 & -4.689 & -6.239 \\
$\mathbf{3}$ & 214.787 & 32.620 & $6.39 \mathrm{e}-10$ & $-7.285^{\mathrm{i}}$ & -3.802 & -6.057 \\
\hline
\end{tabular}

319 Regarding the output of Johansen cointegration (Johansen, 1988; 1991) he has engendered two 320 statistics, trace statistic and Eigenvalues. The result of trace statistics and Eigenvalues for the KSA

321 assume that there are at least four cointegration relationships that exist among cited variables and

322 the null hypothesis of no cointegration can be rejected. The results of the Johansen test are reported

323 in Table 5.

324 Table 5. Johansen Cointegration Test.

\begin{tabular}{lcccc}
\hline Hypothesized No. of CE(s) & Eigenvalue & Trace statistic & 5\% critical value & Prob. $^{\text {a }}$ \\
\hline None * & 0.553 & 83.834 & 69.818 & 0.002 \\
At most 1 * & 0.466 & 53.191 & 47.856 & 0.014 \\
At most 2 & 0.341 & 29.309 & 29.797 & 0.056 \\
At most 3 & 0.264 & 13.450 & 15.494 & 0.099 \\
At most 4 & 0.045 & 1.788 & 3.841 & 0.181 \\
\hline
\end{tabular}

325

326

327

328

329

330

* Trace test indicates 1 co-integrating equations at the $5 \%$ level of significance

a indicates MacKinnon-Haug-Michelis (MHM) p values of MacKinnon et al. (1999)

In the same order, we apply the minimization of AIC and SC (the lag length is used to be 1) to find the order of lags. The order of optimal lags is reported in Table 6. For both AIC and SC, guides to choosing the same optimal lags $(1,0,0,0,1)$.

Table 6. Order of optimal lags.

\begin{tabular}{lccccc}
\hline Number of lags & AIC & SIC & Number of lags & AIC & SIC \\
\hline$(1,0,0,0,0)$ & -1.267 & -0.966 & $(1,1,0,1,0)$ & -1.282 & -0.895 \\
$(1,1,0,0,0)$ & -1.345 & -1.000 & $(1,1,0,0,1)$ & -1.351 & -0.963 \\
$(1,0,1,0,0)$ & -1.309 & -0.964 & $(1,1,1,1,0)$ & -1.252 & -0.821 \\
\hline
\end{tabular}




\begin{tabular}{llllll}
\hline$(1,0,0,1,0)$ & -1.190 & -0.846 & $(1,1,1,0,1)$ & -1.335 & -0.904 \\
$(1,0,0,0,1)$ & $\mathbf{- 1 . 3 7 2}$ & $\mathbf{- 1 . 0 2 7}$ & $(1,1,1,1,1)$ & -1.251 & -0.777 \\
$(1,1,1,0,0)$ & -1.370 & -0.984 & & & \\
\hline
\end{tabular}

Italicized and bold statistics denote the minimized AIC and SIC values.

332 In the second step, we estimate Eq. (4) to evince the long-run and short-run coefficients based 333 on sample data between 1980 and 2019 for the KSA by applying ARDL technique (Table 7). The 334 empirical results display that the lowest value of the 1-year lag in $\mathrm{CO}_{2}$ emissions coefficient by 335 0.220. Furthermore, the results of EPC indicate a long-run and short-run positive effect on $\mathrm{CO}_{2}$ 336 emissions. More precisely, a 1\% increase in EPC will lead towards $3.048 \%$ increase in 337 environmental degradation. The result is in line with previous studies of Akpan et al. (2012); Bella 338 et al. (2014); Cetin et al. (2018) and Kahouli (2018) who detected a positive and significant link 339 among energy and $\mathrm{CO}_{2}$ emissions in the short-run and the long-run.

Likewise, EPC contributes to an important volume of $\mathrm{CO}_{2}$ emissions in the $\mathrm{KSA}$ economy, 341 which requires policymakers to design a policy that decreases EPC through the provision of 342 economic incentives for energy saving. However, the coefficient of MT is negative and significant 343 in the long-run which implies that this variable decelerates environment degradation for the KSA.

344 Precisely, a $1 \%$ increase in MT may decrease $\mathrm{CO}_{2}$ emissions by $0.174 \%$. These results support the 345 finding of Kahouli (2018); Wang et al. (2020) and Zameer et al. (2020) since it shows that MT 346 reduces $\mathrm{CO}_{2}$ emissions. This is due to the fact that technical progress is able to degrade $\mathrm{CO}_{2}$ 347 emissions due to government decisions which incite domestic producers to exploit 348 environmentally friendly technologies. Therefore, MT in the shape of computers and 349 communication are environmentally friendly. Otherwise, the modern technology transferred to the 350 KSA promotes environment quality. The Government of the KSA needs to consolidate input in 351 R\&D and ICT for higher technological strength which will be favorable for protection of the 352 environment. 
In addition, the short-run estimate of $\mathrm{CO}_{2}$ emissions with respect to TCG is negative and 354 significant at the $10 \%$ level. In more details, a $1 \%$ increase in TCG may decrease $\mathrm{CO}_{2}$ emissions 355 by $0.121 \%$. Nevertheless, in the long-run this coefficient is insignificant indicating that TCG has 356 no impact on EnvQ, which suggests that TCG is not helpful to the environment of the KSA, and it 357 does not accompany any contribution in environmental degradation. One probable reason for this 358 insignificance relation is that the KSA has satisfied their need by funding the transfer of technical 359 and managerial skills of technology. Finally, the coefficient of FD is positive and significant at the $36010 \%$ level. It shows that a $1 \%$ increase in FD leads to rise $\mathrm{CO}_{2}$ emissions by about $0.293 \%$. The 361 results are in line with the findings of Ali et al. (2016); Kahouli (2018); Shahbaz et al. (2020) and 362 Acheampong et al. (2020) who confirm the existence of a significant relationship between FD and 363 EnvQ. The development of the financial sector of the Saudi economy plays a very dynamic role in 364 economic growth which directly affects EPC, and therefore has an environmental degradation 365 effect.

The coefficient of lagged error term i.e. ECM are negative and statistically significant at $5 \%$ 367 level confirmed that the long-run relationship among EPC, technological transfer (MT and TCG), 368 FD and EnvQ exist in the case of the KSA economy. In the same order, we apply numerous 369 diagnostic tests to confirm the stability of the model. The results of these tests are reported in the 370 lower portion of Table 7. It is established that there is no serial correlation and heteroscedasticity 371 in the model according to Breusch-Godfrey serial correlation LM test. Moreover, the value of R2 372 for the model shows goodness of fit. The F-statistic which measures the joint significance of all 373 regressors in the model is statistically significant at the $1 \%$ level. The Durbin-Watson statistic is 374 about two; thus, we can deduce the absence of autocorrelation among residuals (prediction errors) 375 from a regression analysis. Besides, the results of sensitivity analysis of CUSUM and CUSUMsq 
376 tests suggest that the model applied in this paper is well proven. The results of both the graphs are 377 exposed in Figs 1 and 2 (Appendix.2.). Both lines plotted within the two straight lines, which 378 bound by $5 \%$ level of significance. Otherwise, the plots of both statistics are within the boundaries, 379 which establish that the pollution model does not violate any assumption. Hence, the model is 380 stable and estimated results are trusted and well considered for policy practices.

381 Table 7. Estimated coefficients from ARDL model.

\begin{tabular}{|c|c|c|c|c|c|}
\hline \multicolumn{6}{|c|}{ Dependent variable: $\Delta \ln E n v Q$} \\
\hline \multicolumn{3}{|c|}{ Short-run results: ARDL $(1,0,0,0,1)$} & \multicolumn{3}{|c|}{ Long-run results } \\
\hline Regressors & Coefficients & t statistics & Regressors & Coefficients & t statistics \\
\hline$\Delta \ln \operatorname{EnvQ}(-1)$ & $-2.95 \mathrm{E}-05$ & $-0.027 * *$ & $\operatorname{lnEPC}$ & 1.386 & $2.914 *$ \\
\hline$\triangle \operatorname{lnEPC}$ & 0.106 & $0.097 *$ & $\operatorname{lnMT}$ & -0.174 & $-3.916 *$ \\
\hline$\Delta \ln \mathrm{MT}$ & -0.019 & $-0.390 *$ & $\ln \mathrm{TCG}$ & -0.097 & -0.068 \\
\hline$\Delta \ln T C G$ & -0.121 & $-1.356 * * *$ & $\operatorname{lnFD}$ & 0.293 & $1.729 * *$ \\
\hline$\Delta \operatorname{lnFD}$ & 0.066 & $1.384^{*}$ & Constant & 1.161 & $0.447 *$ \\
\hline$\Delta \operatorname{lnFD}(-1)$ & -0.248 & $-1.699 *$ & & & \\
\hline $\operatorname{ECM}(-1)$ & -0.301 & $-2.152 *$ & & & \\
\hline \multicolumn{6}{|c|}{ Diagnostic test statistics } \\
\hline LM Test: & 1.374 & & & & \\
\hline F-statistics & $2.334 *$ & & & & \\
\hline ARCH test & 0.458 & & & & \\
\hline Durbin-Watson & 1.638 & & & & \\
\hline R-squared & 0.797 & & & & \\
\hline \multicolumn{6}{|c|}{ Stability Analysis } \\
\hline CUSUM & Stable & & & & \\
\hline CUSUMSQ & Stable & & & & \\
\hline
\end{tabular}

Note: *, **and *** show significance at $1 \%, 5 \%$ and $10 \%$ respectively.

383

384

385

\subsection{The VECM Granger causality tests}

The existence of cointegration among series approves that there ought to be at least four causal relationships; however, it fails to give its direction. Likewise, the present research investigates the direction causal relationship by applying error-correction models based Granger causality tests. Such knowledge is useful in making suitable environmental, energy, technological and financial policies for sustainable development in the case of the KSA (Fig.1). The results on the direction of the long-run and short-run Granger causality are stated in Table 8. Regarding the long-run 
causality, all the ECT coefficients are negative and statistically significant proposing bi-directional causal relationships between the variables (except TCG). Otherwise, our results find that there is an indication of four causal relationships. First causal relationships from EPC, MT, TCG and FD to the environment. Second causal relationships from environment, MT, TCG and FD to EPC. Third causal relationships from environment, EPC, TCG and FD to MT. Fourth causal relationships from environment, EPC, MT and TCG to FD. Nevertheless, an exception is shown for the TCG equation, which is negative and not statistically significant. This suggests an absence of long-run causality from the environment, EPC, MT and FD to TCG. This analysis supports the argument that FD improves EnvQ by prompting the firms to implement advanced technology which emits less $\mathrm{CO}_{2}$ emissions during production and/or consumption. These findings are consistent with Talkudar and Meisner (2001); Shabaz et al. (2013) and Avom et al. (2020) who suggest that ICT affects $\mathrm{CO}_{2}$ emissions through energy and FD. Besides, EPC is Granger caused by FD is consistent with the view studied by Shabaz and Lean (2012) that the financial sector enables firms to adopt advanced and efficient electric technology during the production and/or consumption.

In the same order, results in Table 8 reveal the evidence of three short-run bidirectional granger causality confirming the presence of so-called feedback hypothesis among EPC and environment; MT and environment; EPC and MT. Besides, three short-run unidirectional causal relationships exist: from FD to EPC, from TCG to MT and finally from environment and TCG to FD. The results imply that MT is suitable in improving EnvQ by reducing $\mathrm{CO}_{2}$ emissions. Besides, MT facilitates the development of smart public transport modes, the reduction in the EPC of household appliances or even the optimization of the management of lighting, heating and air conditioning in industrial buildings, etc. In the context of the KSA, it is clear that MT slows down EPC which stimulates a 
413 higher quality of environment. Our results are consistent with those of Tang and Tan (2013);

414 Kahouli (2018); Zafar et al. (2020) who find a bidirectional causality between EPC and

415 technological transfer. In the same context, FD can lead to increased EPC by encouraging

416 consumers to borrow money to buy expensive items. Which allows cheaper and easier access to

417 financial capital, which can be used on the one hand to develop existing businesses, and on the

418 other hand to launch new projects. Consequently, companies will increase their economic activity

419 and, subsequently, the demand for energy affecting as a result environment quality (Gaies et al.,

420 2019; Acheampong et al., 2020).

421 Table 8. Results of VECM Granger causality analysis.

\begin{tabular}{|c|c|c|c|c|c|c|}
\hline \multirow[b]{3}{*}{ Variables } & \multicolumn{6}{|c|}{ Direction of causality } \\
\hline & \multicolumn{5}{|c|}{ Short run } & \multirow{2}{*}{$\frac{\text { Long run }}{\mathrm{ECT}_{\mathrm{t}-1}}$} \\
\hline & $\Delta \ln E n v Q$ & $\Delta \ln \mathrm{EPC}$ & $\Delta \operatorname{lnMT}$ & $\triangle \ln T C G$ & $\Delta \ln F D$ & \\
\hline \multirow[t]{2}{*}{$\Delta \operatorname{lnEnvQ}$} & - & 9.590 & 3.431 & 0.502 & 2.818 & -0.016 \\
\hline & & $(0.003)^{*}$ & $(0.072)^{* * *}$ & $(0.482)$ & $(0.101)$ & $(-0.745) * *$ \\
\hline \multirow[t]{2}{*}{$\triangle \ln E P C$} & 4.293 & - & 4.064 & 0.063 & 10.319 & -0.0003 \\
\hline & $(0.045)^{* *}$ & & $(0.051)^{* * *}$ & $(0.801)$ & $(0.002)^{*}$ & $(-0.0667)^{*}$ \\
\hline \multirow[t]{2}{*}{$\Delta \operatorname{lnMT}$} & 3.128 & 3.113 & - & 0.021 & 0.676 & -0.021 \\
\hline & $(0.085) * * *$ & $(0.086)^{* * *}$ & & $(0.885) * *$ & $(0.416)$ & $(-0.410) * * *$ \\
\hline \multirow[t]{2}{*}{$\Delta \operatorname{lnTCG}$} & 0.002 & 1.297 & 2.836 & - & 0.012 & -0.139 \\
\hline & $(0.962)$ & $(0.262)$ & $(0.100)$ & & $(0.91)$ & $(-5.008)$ \\
\hline \multirow[t]{2}{*}{$\Delta \operatorname{lnFD}$} & 2.660 & 1.100 & 3.725 & 8.7E-07 & - & -0.041 \\
\hline & $(0.111)^{* *}$ & $(0.301)$ & $(0.061)^{* * *}$ & $(0.999)^{*}$ & & $(-1.847) * *$ \\
\hline
\end{tabular}

Note: *, **and *** show significance at $1 \%, 5 \%$ and $10 \%$ respectively.

423 Finally, several policy implications could be derived from this study. First, these results call

424 the policymakers and the government of the KSA for more consideration in the subject of

425 environmental protection, since electric power and FD cause environmental degradation (in the

426 short-run and long-run). Thus, the KSA may impose some pollution control policies such as raising

427 the environmental taxes, positioning restraints on activities source of environmental degradation,

428 promising academic institutions and environmental projects that may explain how to use and apply

429 the methods of environment protection. At this level, policy makers have to promote and 
430 consolidate the environment quality, and increase the utilization of cleaner energy sources in order

431 to decrease $\mathrm{CO}_{2}$ emissions and to develop the FD sector. Second, the technological transfer has

432 improved the environment quality in the KSA. Government willing to reduce EPC has been clear

433 with different implemented legal constraints to use best products in terms of electricity use taking

434 into account technological innovation in this field. This shows that the KSA government is already

435 on the right path in improving the living standard of the nation by implementing environmental

436 friendly projects.

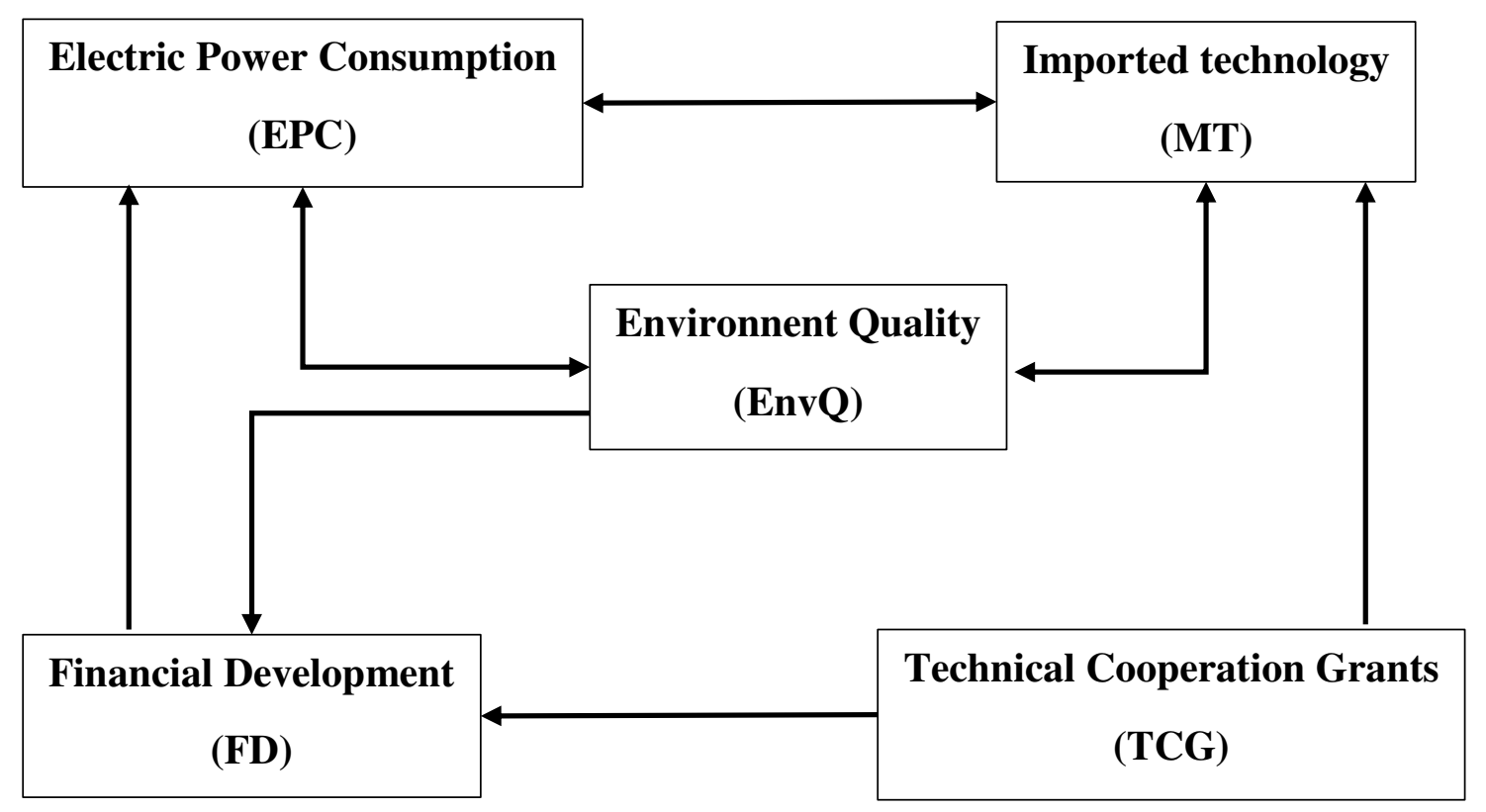

Fig. 1. Pairwise Granger causality results.

\section{6. Conclusion and policy implications}

439 One of the most important strategic objectives of Saudi Arabia 2030 vision is to support efforts 440 and commitment to deal with environmental and economic issues. In this context, this paper 441 examines the effect of relevant technological and economic factors contributing to promote the 442 EnvQ. In the same way, we focus on the effect of the technological transfer (MT and TCG) on $443 \mathrm{CO}_{2}$ emissions by integrating several variables such as EPC and FD for the KSA for the period 
444 1980-2019. For the empirical purpose, our intention was to apply multi-steps techniques to 445 investigate the relationships between EPC, technological transfer, FD and EnvQ. Precisely, we 446 have applied the ADF and PP unit root tests in order to verify the order of integration of the 447 underlying data series which is I (1). Likewise, we have studied and verified the existence of 448 cointegration among $\mathrm{CO}_{2}$ emissions and their determinants by using the ARDL cointegration 449 approach. In the final part of our analysis we have applied the VECM Granger causality to detect 450 the direction of causality. In the light of our empirical results, we have concluded that there is 451 mutual dependence between EPC and $\mathrm{CO}_{2}$ emissions in the short-run and the long-run. Besides, 452 we have concluded that the development of the financial sector of the KSA plays an important role 453 which is direct and dynamic for the improvement of environment quality. Accordingly, the 454 technological transfer affects negatively the EPC. So, EPC has also proven to be an important 455 factor in increasing $\mathrm{CO}_{2}$ emissions. It is evident that there is a strong relation among FD, 456 technologic transfer, EPC and environment for the KSA economy.

457 This result contributes to designing some technological, environmental and financial policies 458 for the KSA. In fact, the policy makers ought to create and to support environmental protection 459 and the green economy. Additionally, the importance of FD in the KSA economy increases the 460 share of the energy sector without harming the environment. We are well aware that the 461 government is moving towards a non-petroleum economic diversification strategy to have more 462 investment flows in the energy domain while encouraging the technological transfer. Therefore, 463 to achieve this, the government is increasingly subsidizing technological projects aimed at 464 reducing energy consumption and thus having a beneficial effect on the environment. In fact, this 465 approach makes it possible to maintain environmental stability and to avoid any negative effects. 466 Likewise, the incorporation of energy efficient technologies into the energy electric segment of 
467 the country can be a means of protecting the quality of the overall environment. For this raison,

468 the KSA aims to conserve electricity or use it more efficiently for consumers. Thus, the 469 comprehensive approach to energy policy aims to reduce cost disparities through less subsidies to 470 conventional energy. In this regard, it is necessary to adopt techniques of the cost of energy over

471 several years such as that provided for in their vision 2030. Indeed, policymakers should seek and 472 encourage cleaner sources of energy consumption. They should develop policies for the 473 development of electricity networks in the various cities of the country to achieve energy savings.

474 The application of this type of policy makes it possible to reduce $\mathrm{CO}_{2}$ emissions. In addition, 475 applying a smart tax system at the same time helps prevent damage to the environment. To 476 conclude, encouraging the technological transfer, facility spillover knowledge, promoting

477 innovation and consolidating R\&D activities by financing and support of electric energy sector 478 strategies constitutes the main locomotive to improve the environment quality for the KSA.

Authors' contributions Bassem Kahouli and Benayan Bani Alrasheedy: Conceptualization,

481 Formal analysis, Validation. Nahla Chaaben: Data curation, Software, Writing - original draft.

482 Bassem Kahouli \& Rabab Triki: Methodology, Supervision, Writing - review \& editing.

483 Funding: This research has been funded by Scientific Research Deanship at University of Ha'il 484 Saudi Arabia through project number RG-191319.

485 Data availability The data are available upon demand by request to the corresponding author.

486 Compliance with ethical standards

487 Competing interests The authors declare that they have no competing interests.

488 Ethics approval and consent to participate Not applicable.

489 Consent for publication Not applicable. 
490 Appendix

491 Appendix.1. A summary of variables.

\begin{tabular}{clcc}
\hline Variable & Meaning & Unit & Source \\
\hline EnvQ $_{\mathrm{t}}$ & $\mathrm{CO}_{2}$ emissions from electricity and & \% of total fuel combustion. & WDI(2019) \\
& heat production. & kWh per capita. & WDI(2019) \\
$\mathrm{EPC}_{\mathrm{t}}$ & Electric power consumption. & \% of commercial service & $\mathrm{WDI}(2019)$ \\
$\mathrm{MT}_{\mathrm{t}}$ & Imported technology. & imports. & \\
& & Current U.S. dollars. & WDI(2019) \\
$\mathrm{TCG}_{\mathrm{t}}$ & Technical cooperation grants. & $\%$ of GDP. & $\mathrm{WDI}(2019)$ \\
$\mathrm{FD}_{\mathrm{t}}$ & Financial development. & &
\end{tabular}

492

WDI (2019): World Development Indicators database, 2019.

493

494 


\section{Appendix.2.}

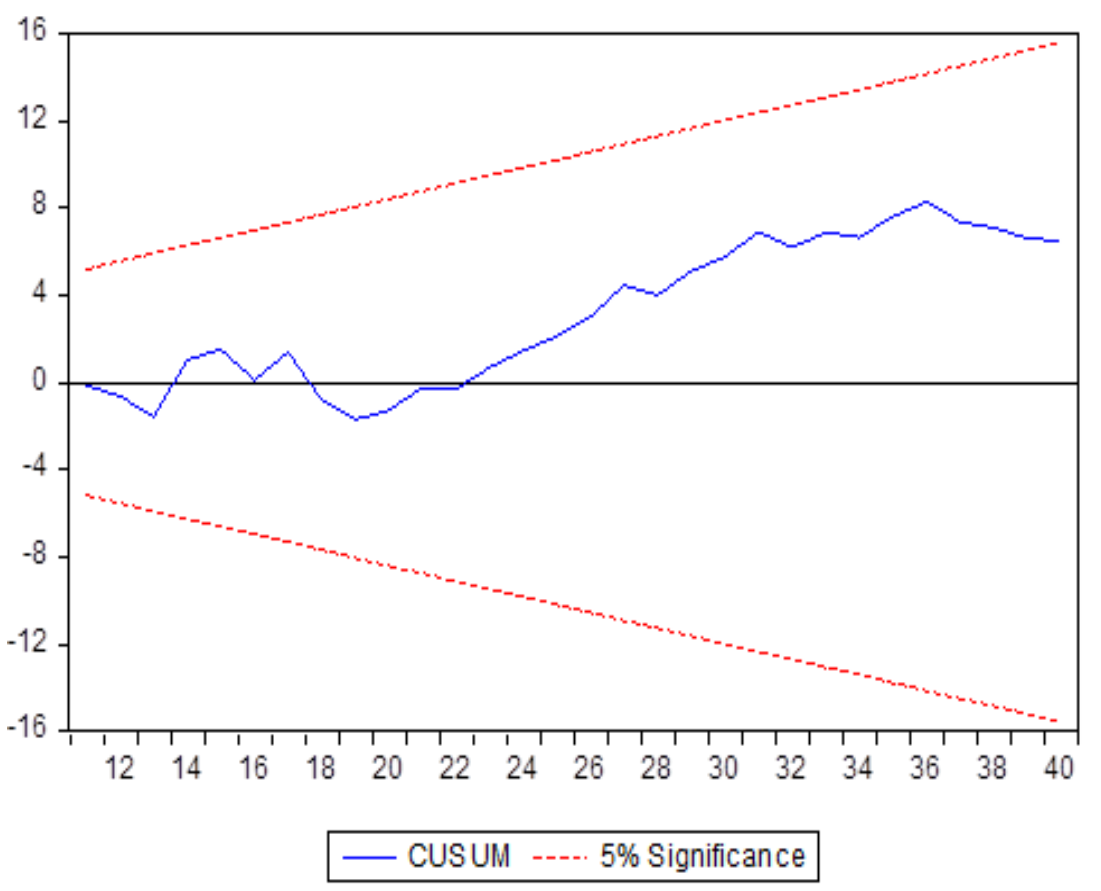

Fig. A.1. Plot of CUSUM.

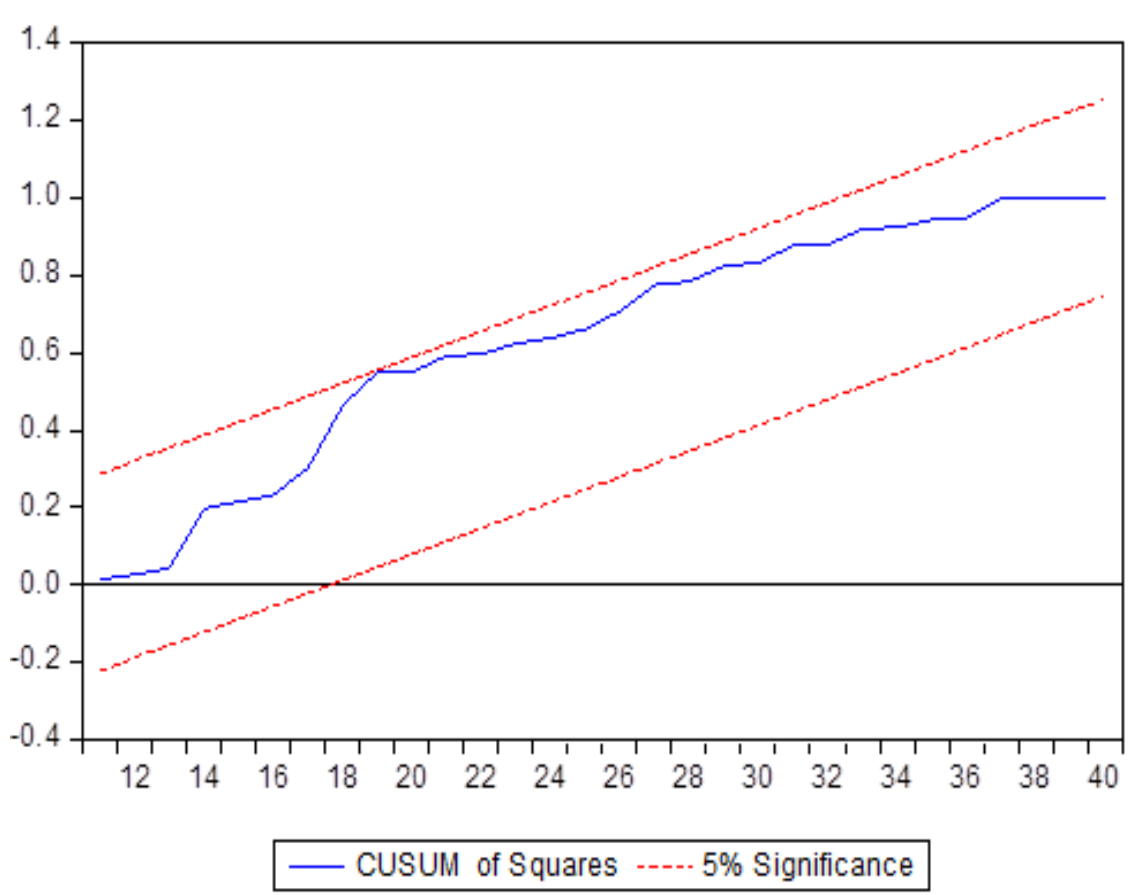

Fig. A.2. Plot of CUSUMsq. 


\section{References}

Acheampong, A. O., Amponsah, M., Boateng, E. (2020). Does financial development mitigate carbon emissions? Evidence from heterogeneous financial economies. Energy Economics, 104768.

Akpan, G. E., Akpan, U. F. (2012). Electricity consumption, carbon emissions and economic growth in Nigeria. International Journal of Energy Economics and Policy, 2(4), 292.

Ali, W., Abdullah, A., Azam, M. (2016). The dynamic linkage between technological innovation and carbon dioxide emissions in Malaysia: an autoregressive distributed lagged bound approach. International Journal of Energy Economics and Policy, 6(3), 389-400.

Ali, W., Rahman, I. U., Zahid, M., Khan, M. A., Kumail, T. (2019). Do technology and structural changes favour environment in Malaysia : An ARDL-based evidence for environmental Kuznets curve. Environment, Development and Sustainability, 1-24.

Alola, A. A., Bekun, F. V., Sarkodie, S. A. (2019). Dynamic impact of trade policy, economic growth, fertility rate, renewable and non-renewable energy consumption on ecological footprint in Europe. Science of the Total Environment, 685, 702-709.

Altıntaş, H., Kassouri, Y. (2020). The impact of energy technology innovations on cleaner energy supply and carbon footprints in Europe: A linear versus nonlinear approach. Journal of Cleaner Production, 276, 124140.

Aluko, O. A., Obalade, A. A. (2020). Financial development and environmental quality in subSaharan Africa: Is there a technology effect? Science of The Total Environment, 747, 141515.

Amri, F. (2018). Carbon dioxide emissions, total factor productivity, ICT, trade, financial development, and energy consumption: testing environmental Kuznets curve hypothesis for Tunisia. Environmental Science and Pollution Research, 25(33), 33691-33701.

Avom, D., Nkengfack, H., Fotio, H. K., Totouom, A. (2020). ICT and environmental quality in Sub-Saharan Africa: Effects and transmission channels. Technological Forecasting and Social Change, 155, 120028.

Bekhet, H. A., Matar, A., Yasmin, T. (2017). CO2 emissions, energy consumption, economic growth, and financial development in GCC countries: Dynamic simultaneous equation models. Renewable and Sustainable Energy Reviews, 70, 117-132.

Bella, G., Massidda, C., Mattana, P. (2014). The relationship among CO2 emissions, electricity power consumption and GDP in OECD countries. Journal of Policy Modeling, 36(6), 970985.

Cetin, M., Ecevit, E., Yucel, A. G. (2018). The impact of economic growth, energy consumption, trade openness, and financial development on carbon emissions: empirical evidence from Turkey. Environmental Science and Pollution Research, 25(36), 3658936603.

Cheng, C., Ren, X., Wang, Z. (2019). The impact of renewable energy and innovation on carbon emission: an empirical analysis for OECD countries. Energy Procedia, 158, 35063512.

Demir, C., Cergibozan, R., Ari, A. (2020). Environmental dimension of innovation: time series evidence from Turkey. Environment, Development and Sustainability, 22(3), 2497-2516. 
Eren, B. M., Taspinar, N., Gokmenoglu, K. K. (2019). The impact of financial development and economic growth on renewable energy consumption: Empirical analysis of India. Science of the Total Environment, 663, 189-197.

Farhani, S., Ozturk, I. (2015). Causal relationship between CO 2 emissions, real GDP, energy consumption, financial development, trade openness, and urbanization in Tunisia. Environmental Science and Pollution Research, 22(20), 15663-15676.

Gaies, B., Kaabia, O., Ayadi, R., Guesmi, K., Abid, I. (2019). Financial development and energy consumption: Is the MENA region different? Energy Policy, 135, 111000.

Halicioglu, F. (2009). An econometric study of CO2 emissions, energy consumption, income and foreign trade in Turkey. Energy Policy, 37(3), 1156-1164.

Hodson, E. L., Brown, M., Cohen, S., Showalter, S., Wise, M., Wood, F., Cleary, K. (2018). US energy sector impacts of technology innovation, fuel price, and electric sector $\mathrm{CO} 2$ policy: Results from the EMF 32 model intercomparison study. Energy Economics, 73, 352370.

Ibrahiem, D. M. (2020). Do technological innovations and financial development improve environmental quality in Egypt? Environmental Science and Pollution Research, 1-13.

Jayanthakumaran, K., Verma, R., Liu, Y. (2012). CO2 emissions, energy consumption, trade and income: a comparative analysis of China and India. Energy Policy, 42, 450-460.

Johansen, S. (1988). Statistical analysis of cointegration vectors. Journal of economic dynamics and control, 12(2-3), 231-254.

Kahouli, B. (2018). The causality link between energy electricity consumption, CO2 emissions, RD stocks and economic growth in Mediterranean countries (MCs). Energy, 145, 388-399.

Kamel, A. H., Shaqlaih, A. S., Ibrahim, E. A. (2015). Model inference using the Akaike information criterion for turbulent flow of non-Newtonian crude oils in pipelines. Petroleum Science, 12(3), 492-500.

Khan, N., Baloch, M. A., Saud, S., Fatima, T. (2018). The effect of ICT on CO 2 emissions in emerging economies: does the level of income matters? Environmental Science and Pollution Research, 25(23), 22850-22860.

Mansouri, N. Y., Crookes, R. J., Korakianitis, T. (2013). A projection of energy consumption and carbon dioxide emissions in the electricity sector for Saudi Arabia: The case for carbon capture and storage and solar photovoltaics. Energy Policy, 63, 681-695.

Mariano, J. D. A., Santos, F. R., Brito, G. W., Junior, J. U., Junior, E. F. C. (2016). Hydro, thermal and photovoltaic power plants: A comparison between electric power generation, environmental impacts and $\mathrm{CO} 2$ emissions in the Brazilian scenario. International Journal of Energy and Environment, 7(4), 347.

Nguyen, T. T., Pham, T. A. T., Tram, H. T. X. (2020). Role of information and communication technologies and innovation in driving carbon emissions and economic growth in selected G-20 countries. Journal of Environmental Management, 261, 110162.

Ouyang, Y., Li, P. (2018). On the nexus of financial development, economic growth, and energy consumption in China: New perspective from a GMM panel VAR approach. Energy Economics, 71, 238-252.

Peng, X., Tao, X. (2018). Decomposition of carbon intensity in electricity production: Technological innovation and structural adjustment in China's power sector. Journal of Cleaner Production, 172, 805-818. 
Rumayor, M., Dominguez-Ramos, A., Perez, P., Irabien, A. (2019). A techno-economic evaluation approach to the electrochemical reduction of $\mathrm{CO} 2$ for formic acid manufacture. Journal of CO2 Utilization, 34, 490-499.

Sadorsky, P. (2011). Financial development and energy consumption in Central and Eastern European frontier economies. Energy policy, 39(2), 999-1006.

Shahbaz, M. (2013). Does financial instability increase environmental degradation? Fresh evidence from Pakistan. Economic Modelling, 33, 537-544.

Shahbaz, M., Lean, H. H. (2012). Does financial development increase energy consumption? The role of industrialization and urbanization in Tunisia. Energy policy, 40, 473-479.

Shahbaz, M., Haouas, I., Sohag, K., Ozturk, I. (2020). The financial developmentenvironmental degradation nexus in the United Arab Emirates: the importance of growth, globalization and structural breaks. Environmental Science and Pollution Research, 1-15.

Shahbaz, M., Khan, S., Tahir, M. I. (2013). The dynamic links between energy consumption, economic growth, financial development and trade in China: fresh evidence from multivariate framework analysis. Energy economics, 40, 8-21.

Sinha, A., Shah, M. I., Sengupta, T., Jiao, Z. (2020). Analyzing technology-emissions association in Top-10 polluted MENA countries: How to ascertain sustainable development by quantile modeling approach. Journal of Environmental Management, 267, 110602.

Talukdar, D., Meisner, C. M. (2001). Does the private sector help or hurt the environment? Evidence from carbon dioxide pollution in developing countries. World development, 29(5), 827-840.

Tang, C. F., Tan, E. C. (2013). Exploring the nexus of electricity consumption, economic growth, energy prices and technology innovation in Malaysia. Applied Energy, 104, $297-$ 305.

United Nations. The Sustainable Development Goals Report 2018. United Nations Publications.

Wang, B., Wang, Z. (2018). Imported technology and CO2 emission in China: Collecting evidence through bound testing and VECM approach. Renewable and Sustainable Energy Reviews, 82, 4204-4214.

Wang, Z. (2019). Does biomass energy consumption help to control environmental pollution? Evidence from BRICS countries. Science of the total environment, 670, 1075-1083.

Wang, Z., Xia, C., Xia, Y. (2020). Dynamic relationship between environmental regulation and energy consumption structure in China under spatiotemporal heterogeneity. Science of The Total Environment, 738, 140364.

Wattana, S., Wattana, B. (2020). An Assessment of the Impacts of Renewable Energy Policies on the Thai Electricity Generation Sector. International Energy Journal, 20(2).

Xu, Z., Baloch, M. A., Meng, F., Zhang, J., Mahmood, Z. (2018). Nexus between financial development and CO 2 emissions in Saudi Arabia: analyzing the role of globalization. Environmental Science and Pollution Research, 25(28), 28378-28390.

Yeager, K., Dayo, F., Fisher, B., Fouquet, R., Gilau, A., Rogner, H. H., Lustig, N. (2012). Energy and economy. Global Energy Assessment (GEA), 385-422.

Zafar, M. W., Shahbaz, M., Sinha, A., Sengupta, T., Qin, Q. (2020). How renewable energy consumption contribute to environmental quality? The role of education in OECD countries. Journal of Cleaner Production, 122149.

Zameer, H., Yasmeen, H., Zafar, M. W., Waheed, A., Sinha, A. (2020). Analyzing the association between innovation, economic growth, and environment: divulging the 
importance of FDI and trade openness in India. Environmental Science and Pollution Research, 1-15.

Zhang, N., Zhou, P., Choi, Y. (2013). Energy efficiency, CO2 emission performance and technology gaps in fossil fuel electricity generation in Korea: A meta-frontier non-radial directional distance function analysis. Energy Policy, 56, 653-662. 